\title{
UNIVERSIDAD Y DESEMPEÑO ACADÉMICO. DISTORSIONES Y ANOMALÍAS DE LA CULTURA EVALUATIVA EN CHILE
}

\section{UNIVERSITY AND ACADEMIC PERFORMANCE. DISTORTIONS AND ANOMALIES OF THE EVALUATIVE CULTURE IN CHILE}

\section{JOSÉ SANTOS HERCEG*}

Resumen: El texto expone un acercamiento crítico a la cultura evaluativa existente en la actualidad en la mayoría de las universidades chilenas. Dicho acercamiento se hace a través de un análisis del sistema de evaluación del desempeño académico, en particular el que refiere a la investigación y la publicación. Se sostiene que existen distorsiones o anomalías provocadas por este sistema en lo relativo a la escritura, al cuerpo académico y al trabajo académico que provocan consecuencias negativas sobre el desarrollo de la actividad universitaria.

Palabras ClaVe: Universidad, investigación, publicación, desempeño académico, evaluación.

AвSTRACT: This text presents a critical approach to the evaluative culture currently present in most Chilean universities. This is done by analyzing the system of evaluation of the academic performance, particularly regarding research and publication. It is argued that there are distortions or anomalies caused by this system with regards to writing, the academic faculty and academic work which have had negative consequences on the development of university activity.

Keywords: University, Research, Publication, Academic Performance, Evaluation.

Recibido: 2019-07-17. Aceptado: 2020-03-23.

$\mathrm{H}$ ASTA HACE TAN SOLO UNAS décadas, la evaluación era una actividad casi marginal en las universidades chilenas. Se trataba de una función entre otras, sin protagonismo, en tanto que se la concebía tan solo como un instrumento utilizado en la administración de las instituciones.

* Doctor en Filosofía. Académico Instituto de Estudios Avanzados (IDEA), USACH, Santiago, Chile. Correo electrónico: josé.santos@usach.cl. Orcid: https://orcid.org/0000-0001-5425-2340. 
Como explica muy bien Murphy (2002), la evaluación no tenía un fin en sí misma, sino que una "herramienta de gestión" cuyo objetivo era "encontrar información" que hiciera posible construir un "diagnóstico" (p. 77). Si bien la función propia de la evaluación no ha cambiado, su incidencia ha aumentado radicalmente y el lugar que ocupa hoy en las universidades chilenas ya no es tan solo el de una herramienta de gestión más. A partir de las reformas introducidas en el sistema universitario a principio de los años $80^{1}$, su lugar se ha desplazado hasta convertirse hoy en una actividad infaltable y protagónica que parece inundarlo todo en el mundo académi$\mathrm{CO}^{2}$. Es así como el trabajo universitario completo es objeto de evaluación: los profesores evalúan a sus alumnos y son evaluados por ellos. Los académicos son evaluados por las autoridades, y por sus pares. Los organismos estatales que financian investigación (Fondecyt, Fondart, Conicyt) evalúan a los investigadores, mientras otros organismos estatales evalúan a las instituciones universitarias (CNA). En definitiva, como constatan Valenzuela et al. (2011): "Dentro de las muchas actividades que se realizan en una institución educativa, una que ocupa un lugar central (...) es la relativa a la evaluación" (p. 44).

Como es bien sabido, existen muchas maneras de evaluar; son múltiples las formas de buscar, recopilar, conseguir información. Igualmente, hay diferentes caminos para jerarquizarla y organizarla y, sin duda, existe más de una alternativa para interpretar la información obtenida. Algunas modalidades son expresas, otras tácitas y ocultas; algunas son directas, otras oblicuas; unas son participativas, otras impuestas. Los sistemas de evaluación son, por lo tanto, múltiples y variados. La forma en que se realiza concretamente una evaluación y el sistema evaluativo que se instala están íntimamente vinculados con la "cultura evaluativa" en la que está inserto dicho sistema. Una cultura de evaluación ha sido definida por Valenzuela et al. (2011) como "el conjunto de valores, acuerdos, tradiciones, creencias

\footnotetext{
${ }^{1}$ Como han señalado acertadamente Lampert y Holgado (2001), la evaluación es un fenómeno "característico de la empresa que después fue incorporado al campo pedagógico" (p. 222). En Chile esto se produce con la llamada Nueva ley de Universidades, que corresponde a una serie de Decretos con Fuerza de Ley que la Dictadura dictó entre 1980 y 1981. Como es bien sabido, lo que se hace es, dicho en palabras del entonces Ministro del Interior Sergio Fernández, "introducir el factor competitivo en el sistema universitario" (1981, p. D2). Con ello la universidad chilena se vuelve, según Luis Scherz (2005) una "Universidad-Empresa" (p. 149) e instala la evaluación como uno de sus ejes principales de funcionamiento.

${ }^{2}$ Bernasconi (2010) hace ver que en 2001-2002, de doce universidades estudiadas solo tres tenían sistemas de evaluación periódica de desempeño implementados y en tan solo seis años, "estas evaluaciones habían sido introducidas también en otras cuatro, y en las demás universidades estaban siendo consideradas para pronta implementación" (p. 156).
} 
y pensamientos que una comunidad educativa asigna a la acción de evaluación" (p. 45). Las culturas de evaluación son, por supuesto, múltiples. Ellas son contextual e históricamente dependientes: varían con el paso del tiempo según el lugar en el que surjan. Lo que interesa dilucidar en este escrito, por lo tanto, tiene relación en particular con la cultura evaluativa vigente hoy en las universidades chilenas.

En Chile la evaluación se aprecia generalmente como una carga burocrática, y los comentarios que se escuchan entre los actores tienden a menospreciarla. Esto es un síntoma inequívoco, según han señalado Valenzuela et al. (2011), de que existe "una cultura de evaluación que no necesariamente coincide con lo que muchos consideraríamos "ideal" (p. 46). Con el objetivo de acercarnos a esta disonancia entre lo que lo es y lo que quisiéramos que fuera, comenzaré por un análisis de la cultura evaluativa existente hoy en día en las universidades chilenas. Como se trata de un fenómeno amplio y complejo, en esta oportunidad se tendrá a la vista tan solo un aspecto: la evaluación de los académicos, que son quienes están más sometidos a ella, pues los evalúan todos aquellos con los que se relacionan. Las autoridades universitarias evalúan su "desempeño", los alumnos de la "calidad de la docencia", los organismos que financian investigación de los "resultados". Los académicos hoy en Chile están sometidos constante y permanentemente a evaluación. Entre todas estas será la de su "desempeño" la que nos ocupe, es decir, aquella que implementan las universidades con el fin de averiguar si los académicos han cumplido con su trabajo de manera satisfactoria.

La evaluación del desempeño es hoy para la gran mayoría de los académicos en Chile una instancia incómoda, molesta e incluso llega a ser atemorizante. Esta incomodidad y temor se asocian, según señala Murphy (2002), con tres experiencias. La primera es que la evaluación se perciba como una inspección o examen impuesto desde arriba al que se está sometido forzosamente, y que se inmiscuye en asuntos personales: la información recopilada es acerca de uno y de cómo uno hace su trabajo. Esta es justamente la situación de los académicos en las universidades chilenas. Sin discusión ni crítica, casi sin notarlo siquiera, se nos ha impuesto desde las autoridades universitarias la exigencia de evaluación. Una evaluación en la que estamos atrapados: someterse a ella no es opcional, es una obligación que aceptamos tácitamente junto con la firma de contrato. En este contexto las instituciones exigen, además, acceso completo, total transparencia. Las universidades se arrogan el derecho de hurgar en los rincones más privados de la actividad académica: se inmiscuyen en los recovecos de la investigación, de la labor docente, de la escritura. 
Una segunda experiencia a la que alude Murphy y que lleva a asociar la evaluación con una amenaza, es que la información recopilada se utiliza para tomar medidas represivas que pueden llevar incluso a despidos. En nuestro país las evaluaciones no son experimentadas por los evaluados como una simple recopilación de información, sino que más bien como un enjuiciamiento. Ser evaluado es ser examinado. El informe del examen que haga la institución a partir de la información recolectada es un juicio que puede dejarnos tranquilos por un tiempo, pero que también puede implicar sanciones, algunas de las cuales llegan a ser tan drásticas como la desvinculación de la universidad.

Finalmente, como fuente de percepción de incomodidad según Murphy, está la experiencia de que los resultados de la evaluación simplemente no quedan en nada y se tiene la sensación de haber perdido el tiempo. Esta es una idea extendida entre el estamento académico de las universidades chilenas: nos pasamos enviando informes de actividades que nunca se traducen en nada. La evaluación es experimentada, en general, como un gesto vacío. El fundamento de dicha percepción tiene que ver primordialmente con la convicción de que las evaluaciones, al menos como se han instalado en Chile, no permitirían hacer un diagnóstico ni real ni completo del desempeño de un académico.

Con la finalidad de comprender el origen de esta percepción negativa es necesario aludir, para comenzar, al hecho de que la evaluación a la que estamos sometidos los académicos hoy en Chile es análoga a la que se utiliza en el ámbito económico-industrial. Es decir, la labor académica es evaluada como si las universidades fueran empresas de bienes y servicios. Como servicios se consideran, en primer lugar, la docencia que se ofrece al mercado de estudios: los cursos que se dictan, las tesis que se dirigen. También se toman en cuenta los servicios de gestión universitaria que desempeñan los académicos: dirección de programas de estudios, dirección de departamentos, de instituciones universitarias, asesorías externas, etc. Los bienes que se consideran son principalmente textos (libros, artículos, ponencias, etc.), patentes y proyectos. Los resultados, los productos son casi lo único que se considera en las evaluaciones vigentes hoy en las universidades chilenas.

La cuestión es central, puesto que, como ha escrito Murphy (2002), "la evaluación tiene un impacto en cómo hacemos las cosas" (p. 80). Tapia y Varela (2014) apuntan a la misma idea cuando señalan que "los criterios de evaluación condicionan el desempeño" (p. 82). Lo mismo sostienen Márquez y Cancino (2013): "dependiendo del énfasis que se le dé a los diferentes indicadores y criterios de evaluación esto moldeará el desempeño de 
los trabajadores" (p. 8). Las decisiones acerca del modo en que hacemos clases o incluso los temas sobre los que proponemos cursos o seminarios, así como también la manera de investigar y las decisiones sobre publicaciones (modo, lugar, extensión, etc.), van poco a poco modificándose con la finalidad de obtener una buena evaluación. Aquel instrumento cuya finalidad era medir y diagnosticar termina transformándose en la pauta, en una suerte de criterio, de norma que establece la manera en que deben hacerse las cosas. Estos cambios no son solo formales, sino que se articulan con una alteración a nivel valórico. Murphy (2002) enfatiza la importancia de este punto cuando señala que lo fundamental es "cambiar los valores" (p. 80). Los cambios formales en lo relativo a criterios e indicadores tienen su fundamento en estos nuevos valores: se imponen la eficiencia y la maximización como los prioritarios. La cantidad, por lo tanto, se va imponiendo como criterio valorativo hegemónico. El mejor valorado será el académico más eficiente: el que más publique, el que más cursos imparta, el que más tesis dirija, etc.

Para mostrar lo que se viene diciendo, se atenderá paradigmáticamente a una de las actividades propias del trabajo académico: la investigación. Partiremos de una constatación de facto: la investigación está siendo evaluada casi única y exclusivamente en virtud de las publicaciones. Como bien han escrito Greene y Campos (2012), existe una suerte de "sentido común dominante" para el cual "el resultado legítimo de cualquier investigación es uno solamente: el 'artículo científico' en su acepción más restringida" (p. 2). Explican luego que "[e]l texto escrito -y escrito de cierta manera, siguiendo convenciones anglosajonas importadas de las ciencias 'duras' - pasa a ser la única forma apropiada de comunicar conocimiento" (p. 3). En otro lugar me he referido a este fenómeno en términos de la "tiranía del paper" (Santos Herceg, 2012). Para efectos de la evaluación de desempeño investigativo se consideran fundamental y casi exclusivamente la cantidad de publicaciones en ese formato: el número de paper pasa a ser lo preponderante. La llamada productividad -cantidad de producto- parece ser lo único que interesa evaluar a las universidades cuando se trata de diagnosticar el estado de la investigación.

Es en el ámbito de la economía, puntualmente en el de la industria, donde nacen y se utilizan más originalmente los términos "producción" y "producto". En este contexto, "producto" ha sido definido como "aquello que una empresa (grande, mediana o pequeña), organización (ya sea lucrativa o no) o emprendedor individual ofrece a su mercado de interés para lograr los objetivos que persigue (utilidades, el impacto social, etcétera)" (Vidal, 
2012, p. 98). Un producto, por lo tanto, es algo producido por un agente económico -empresa o emprendedor- con la finalidad de ofrecerlo a un determinado mercado. Es este el sentido con el que la categoría se desplaza al mundo de la investigación universitaria. Así se le entiende cuando se utiliza para hablar de los productos de un determinado proyecto de investigación: como algo que genera un investigador para un mercado académico teniendo como objetivos la obtención de becas, de mejores evaluaciones e incluso de dinero por concepto de estímulos y premios.

Rolando Rebolledo (2014) señala directamente que:

(...) la existencia de esa forma de evaluar por producto ha ido condicionando la forma de trabajo de nuestros investigadores. Publicar a todo precio, resolviendo problemas planteados por algún equipo a la moda, entiéndase a la moda de algunas publicaciones de 'alto impacto', parece ser la regla de oro para devenir un investigador importante". [en línea]

En efecto, a través de la forma evaluativa vigente se ha entronizado el "modelo productivo" en el ámbito del trabajo académico y, muy particularmente, en el de la investigación y la publicación. Prueba de ello es que hoy por hoy casi no encontramos otra forma de referirnos al resultado de nuestro propio trabajo más que en términos de "producción". Felipe Cussen (ver Jofré, 2012) decía en una entrevista: "trabajo como investigador y profesor en una universidad, y en los últimos años se nos ha intentado presionar con una serie de medidas para que seamos 'productivos"' ([en línea]). Nos hemos ido convirtiendo, presionados por el sistema de evaluación de desempeño, en productores, en el sentido puntual de producir textos. De ello depende el éxito o el fracaso, la obtención de premios o la imposición de castigos. Pérez y Guzmán (2015) hacían ver acertadamente que:

Los sistemas de evaluación ya no son un mecanismo para reconocer un trabajo libre y autónomo, sino un mecanismo que traduce el trabajo intelectual en productos tangibles y cuantificables, lo que remite a un proceso de regulación individualizada en el que no se trata de la permanencia sino de la "resistencia" en los procesos de evaluación, especialmente si se asocia con los ingresos económicos. (p. 96)

El sistema evaluativo vigente, con sus estructuras de incentivo a la producción y amenaza de castigo para un académico que no alcanza un nivel aceptable de productividad, ha comenzado a producir una serie de efectos preocupantes e incluso anómalos en la actividad académica, lo que ha lla- 
mado la atención de los investigadores generando críticas ${ }^{3}$. Muñoz, García y López (2014) habla directamente de los "efectos perversos" (p.188) del sistema de evaluación vigente. Greene y Campos (2012), por su parte, señalan que este sistema "tiene como consecuencia la generación de distorsiones en la producción y difusión del conocimiento académico" (p. 1). Con el objetivo de organizar el panorama de crítica existente es posible distinguir al menos tres constelaciones de efectos anómalos. Sin que ello implique una jerarquización, hay, en primer lugar, efectos relacionados con la escritura; en segundo lugar, efectos relacionados con la comunidad o cuerpo académico; y, en tercer lugar, efectos relativos a la actividad académica en general.

En lo que a la escritura se refiere, la evaluación de desempeño asociada a la amenaza y el incentivo tiene como consecuencia casi inmediata un enorme aumento de la producción de artículos, especialmente aquellos que se envían para su publicación a revistas WoS (ex ISI), Scopus y Scielo. Esto, que en principio podría ser deseable, produce un efecto que genera problemas de difícil solución. Dicha producción se vuelve tan enorme que caemos en lo que ha sido calificado de "sobreproducción". Corral (2016) lo ha escrito claramente: "Se produce entonces un efecto de sobreproducción académica, es decir, un incremento en la elaboración de publicaciones" (p. 64). Las condiciones de competencia en que se ha instalado la actividad, necesidad y, en algunos casos, desesperación por publicar, ha desatado una "publiquitis" evidente: inflamación de la publicación.

Puesto que nuestras publicaciones son tratadas como una mercancía, habría que constatar aquí, como segundo efecto constatable, la saturación que ello produce en el mercado al que están dirigidas. Esto se puede observar en dos niveles: en el de los medios de publicación -revistas- y en el de los consumidores -investigadores. Con el fenómeno de la saturación de los medios se alude al hecho de que las revistas están superadas en su capacidad, es decir, literalmente han rebalsado su posibilidad de absorción y publicación de textos. Las revistas chilenas que están en WoS, Scielo -ahora

\footnotetext{
${ }^{3}$ Es interesante constatar que, según informa Ojeda (2017), la evaluación de desempeño ha sido objeto de una fuerte y demoledora crítica en el ámbito empresarial, lo que llevó hace pocos años a que llegara a declararse su desaparición. Aunque esta crítica no es la misma que se puede observar en el ámbito académico, sin embargo, apunta en un sentido cercano. Allí se alude, por ejemplo, al hecho de que esta práctica individualiza, con lo que se atenta contra el trabajo colectivo. Del mismo modo, se ha hecho ver la evaluación de desempeño como una práctica de dominación. Ambos asuntos, como se verá, pueden observarse también en el ámbito académico.
} 
también en Scopus- no estaban ni están preparadas para el aluvión de artículos que les comenzó a caer en los últimos años. Dicho de otra forma, el aumento de producción en términos de cantidad ha sido tan explosivo y de tal magnitud que las revistas simplemente no dan abasto. Los tiempos de espera hasta que un artículo finalmente se publique han alcanzado grados simplemente insostenibles. Hay revistas que se han visto obligadas a cerrar la recepción, pues ya tienen suficientes textos para varios años.

En vista de esta situación, los académicos-productores salen a buscar otros mercados y se dirigen al extranjero. No es ningún secreto que la gran mayoría de las revistas que están en los índices más apetecidos se publican fuera de Chile y, mayoritariamente, en inglés. Los resultados de nuestras investigaciones, aquellas financiadas por instituciones nacionales, ya sea las mismas universidades o Fondecyt, son publicados en revistas extranjeras. Esto, además, se hace gratuitamente, e incluso en algunos casos pagando para ello. Actualmente, muchas universidades ofrecen un servicio gratuito de traducción para que los académicos puedan publicar sus artículos en revistas internacionales. Se ha hablado de la "fuga de cerebros", y la situación actual es, en algunos sentidos, análoga. Estamos frente a una "fuga de ideas", porque los cerebros permanecen en Chile, pero lo que ellos generan emigra. Al respecto Greene y Campos (2012) observan que:

(...) no es inusual que académicos latinoamericanos escojan traducir sus investigaciones y privilegiar la publicación en inglés en desmedro del español. Esto no sólo relega nuestra lengua a un lugar secundario, sino que además previene que trabajos producidos en esta región se den a conocer a un público amplio que no domina el inglés. (p. 2)

La saturación tiene efectos también sobre el trabajo de investigación mismo $^{4}$. Los consumidores de la textualidad científica, es decir, los académicos, no logran dar cuenta de la oferta completa. Ellos simplemente no pueden leer la enorme cantidad de textos que aparecen por cientos diariamente sobre cada tema. Estar al día con la literatura es hoy una tarea prácticamente imposible de lograr. Esto produce al menos dos efectos complicados: por un lado, una gran parte de lo publicado, tal vez la mayor parte, nunca es leído y menos estudiado; su destino es quedar olvidado bajo un cerro de textualidad que aumenta a cada minuto. Por otra parte,

\footnotetext{
${ }^{4}$ El apartado No5 del libro La Tiranía del paper (Santos Herceg, 2020) aborda más extensamente las consecuencias de la "saturación" en lo relativo al trabajo de investigación. En lo que sigue se presentan brevemente algunas de ellas.
} 
la constitución de un corpus bibliográfico de calidad acerca de un tema en particular se vuelve en extremo difícil. Un porcentaje no menor de la enorme cantidad de textos que se publican no son trabajos científicos de calidad, pero para poder distinguirlos hay que hacer la lectura y revisión correspondiente, lo que requiere de una gran cantidad de energía y tiempo. El problema más serio, sin embargo, es que en este contexto dar con los trabajos realmente relevantes sobre un tema se transforma en un asunto casi azaroso: en ocasiones hay que revisar cientos, incluso miles de textos para logarlo.

Este último problema se enlaza causalmente con el hecho indesmentible de que la afiebrada necesidad o deseo de publicar más y más cada vez provoca una baja en la calidad de los trabajos. Como ha escrito Michael Billig (2013): "[ $t$ ]rabajando en las condiciones competitivas del capitalismo académico, los académicos se sienten en la necesidad de continuar publicando independientemente de que tengan algo que decir" (p. 7). De allí que hoy encontremos en el mundo de las publicaciones científicas algunas -tal vez muchas- carentes de toda relevancia, que son el producto de que los investigadores han terminado rigiéndose por el principio de publicar por publicar o, dicho de otra forma, publicar por los puntos. "El supuesto de que se debe publicar porque las publicaciones equivalen a puntos y éstos a dinero, constituiría una práctica en detrimento de la calidad, puesto que favorece mecanismos para 'sobrevivir"' (Tapia y Varela, 2014, p. 91). Schulz y Katime (2003) han llamado "papermanía" a este fenómeno.

Para muchos científicos, la calidad de los trabajos, la originalidad y los aportes importantes han pasado a segundo plano, interesando la cantidad. Hay que engordar el currículum con el mayor número de artículos posible. Cuantos más tenga el investigador, sin importar su calidad, más importante es. Es la papermanía. (p. 51)

Otra constelación de efectos de este sistema de evaluación por productividad atañe al cuerpo académico. Tapia y Varela (2014) ven con claridad que

(...) existe el riesgo ya sea de una sobrevaloración o de una subvaloración de las actividades efectuadas. La posibilidad de que se produzca una injusticia o se premie la simulación de un trabajo pobre o inexistente es un riesgo que surge desde que se descuida la perspectiva cualitativa. (p. 95) 
Un sistema de evaluación que considera tan solo lo cuantitativo refleja un panorama distorsionado. Paradigmáticos y lamentables son los proyectos que le son rechazados a destacados investigadores, intelectuales de los que no es posible poner en duda su trayectoria ni la calidad de su trabajo, porque una evaluación limitada y meramente cuantitativa de su productividad arroja un puntaje paupérrimo. Proyectos maravillosos, con evaluación perfecta en lo referente a su contenido, con una fuerte recomendación de financiamiento se pierden porque el sistema cuantitativo de evaluación curricular por productividad arroja un número muy bajo.

En tanto que la evaluación cuantitativa muestra solamente una porción limitada de la realidad de la actividad académica, se corre el riesgo real de dejar de ver todo lo realizado. Esto podría también provocar la ilusión de que alguien desarrolla una gran actividad cuando, en la realidad, no es así. No faltan los casos de académicos que dedican todo su tiempo exclusivamente a generar artículos publicables en revistas indexadas, es decir, texto escritos, construidos y dispuestos solo con el objeto de que sean aceptados para su publicación, sin que su aporte o contenido sea un tema de preocupación preponderante. La distorsión en términos evaluativos puede ser "provocada" incluso acudiendo a estrategias reñidas con la moral y la ley.

Lo dicho tiene un efecto aún más complejo, pues el sistema de evaluación vigente hoy en Chile provoca una estratificación socio/económica del cuerpo académico. Están, por una parte, lo que son bien evaluados, los exitosos, quienes obtienen los premios, las becas, los financiamientos. Sus líneas de investigación se desarrollan con adecuada dotación de recursos lo que, en la práctica, se traducirá en aún mejores evaluaciones, las que a su vez perpetúan su lugar de privilegio. Ellos han sabido trabajar en consonancia con el sistema de evaluación vigente. Estos académicos cual "hombres de negocio", como ha escrito Rorty (1996), "administran" su carrera y llegan a ser exitosos (p. 127). En el otro extremo del espectro están, como dice Rorty (1996) nuevamente, los fracasados "hidalgos harapientos" (p. 127). Para aquellos que entran dentro de este esquema, la desaparición de temas y líneas de investigación, con la consecuente pauperización, son algunos de los efectos concretos de la imposición de este modelo productivo. La consecuencia, como ha visto muy bien Piña (2013), es un "malestar" entre los académicos (p. 3). Un malestar que bien podría calificarse de resentimiento, puesto que "(...) por un lado, están los académicos con categoría laboral y premios altos y, por otro, aquellos con categoría laboral y estímulo bajo" (p. 3). 
La situación se complica dado que en los sistemas de evaluación vigentes son los mismos académicos, en particular aquellos que han alcanzado las jerarquías más altas, los "exitosos", quienes son convocados a juzgar el desempeño del resto. El sistema de "evaluación por pares" en su momento sirvió para superar malas prácticas como "las relaciones personales, las influencias políticas, o la mera antigüedad, como el criterio dominante para la asignación de mérito y reconocimientos" (Bernasconi, 2010, p. 153). En contexto de competencia como el que se ha instalado en las universidades chilenas, este sistema, sin embargo, muestra su otra cara. "En el caso de los cuerpos académicos, son los mismos colegas integrantes quienes se convierten en verdugos que en un momento dado 'castigan' a sus compañeros con los que conviven cotidianamente" (Pérez y Guzmán, 2015, p. 98). De esta forma, se constituye una comunidad de víctimas y victimarios donde la suspicacia, la desconfianza y la enemistad son habituales.

En esta realidad competitiva y descarnada, que he querido graficar en otro texto usando la idea de un "evolucionismo investigativo" (Santos Herceg, 2014) el trabajo colaborativo desaparece ${ }^{5}$. Pérez y Guzmán (2015) escriben que "en los grupos de investigación se da una competencia para publicar en las revistas de alto factor de impacto, lo cual crea rivalidad entre los investigadores que, dentro de la misma institución, pertenecen a grupos consolidados de investigación" (p. 98). Como observé hace unos años, el hecho de que los investigadores deban competir entre ellos para conseguir una parte del fondo transforma a los colegas en una amenaza, en un peligro para la propia sobrevivencia como investigador (Santos Herceg, 2015, p. 104). En ese contexto, toda posibilidad de colaborar se hace imposible y lo que hay son negociaciones, pactos (de no agresión, de frente común, etc.), convenios, pero no colaboración. Cuando comenzaban a instalarse los sistemas de evaluación y de incentivo, Sylvie Didou (1995) hacía ver con gran agudeza que existían dos riesgos: uno de ellos era la destrucción de la comunidad académica.

Los efectos relativos a la actividad académica misma constituyen otra constelación de consecuencias del sistema de evaluación imperante. Lo primero que salta a la vista es que la carrera por publicar acarrea el abandono

\footnotetext{
${ }^{5}$ De acuerdo con los académicos entrevistados por Tapia y Varela (2014): "Otra apreciación es que la evaluación tal como se comprende y practica en la actualidad se estableció con el objetivo deliberado de fragmentar el trabajo académico y de atomizar a la comunidad" (p. 91).
} 
de otro tipo de funciones propias de la vida académica. Como constata Bermejo (2009), "[e]n este nuevo sistema de evaluación del conocimiento -en el que la propia evaluación pretende constituirse como ciencia- los investigadores y los profesores sólo intentan conseguir aquello que puede ser medible y que les puede ser académicamente rentable" (p. 13). Esto explica, por ejemplo, el que los académicos prioricen las publicaciones rentables -artículos publicados en revistas indexadas- y abandonen la escritura de libros, la participación en eventos académicos o en debates públicos, el cultivo de la relación con los alumnos y los colegas, la difusión de sus investigaciones en ámbitos no académicos, concentrándose en la actividad productiva.

Lo abandonado no son solo ciertas actividades propias de la actividad académica. La desaparición de temas de estudios es otro efecto que este sistema de evaluación ha tenido sobre la investigación. "Los estudios que no tienen cabida en la nueva configuración de la investigación científica son abandonados en su mayoría por los académicos e investigadores, que no ven en ellos posibilidades de desarrollo profesional o de promoción laboral" (Corral, 2016, p. 64). La temática puede ser interesante, importante, relevante, indispensable, pero si no es rentable está en peligro de extinción. Dada la instalación de los valores de la eficiencia y la maximización que provoca el sistema evaluativo vigente, el limitado tiempo del que disponen los investigadores lo dedican a aquellas actividades que al momento de la evaluación le rindan los mejores frutos: aquellas que sean más productivas, es decir, las que otorguen mayores ganancias con el menor costo posible.

La burocratización del trabajo académico es también un evidente efecto de este sistema de evaluación. Se trata de la "carga laboral adicional debida al llenado de formularios y a los trámites administrativos" (Tapia y Varela, 2014, p. 95); que es una queja que se escucha permanente e insistentemente en las universidades. Los mismos autores señalan que:

Los excesos de la llamada "tramititis" harían de la carrera académica una "ruta de puntos", donde abundan los informes y procedimientos repetitivos y engorrosos. Esta carrera de "resistencia" incluye como se ha visto informes anuales, trimestrales, para acreditación de "per l" y para acceder a ingresos adicionales. Y además se exige la presentación de un plan de trabajo anual a cada profesor. (p. 96)

Es un hecho que una porción importante de tiempo la utilizan los académicos en preparar informes para ser evaluados por los pares, por los directivos, por los jefes, por las instituciones, por las instancias que dieron un 
financiamiento o una beca, etc. (Cf.: Santos Herceg, 2015, p. 108). El tiempo sobrante es poco y debe ser maximizado. El modo de trabajar académicamente en Chile, en definitiva, está cada vez más cercano al del hombre de negocios que administra la empresa que es, finalmente, su carrera académica. En relación con los filósofos profesionales escribí hace algún tiempo que estos van tomando la fisonomía de una "mini Pyme" (Santos Herceg, 2011). Todas las decisiones se vuelven estratégicas con la finalidad de obtener una mejor evaluación de desempeño y llegar a ser exitoso.

Hasta este punto se ha podido dar cuenta de la existencia de algunas anomalías y distorsiones que provoca el sistema de evaluación actualmente vigente en Chile en lo referente a la investigación. Saturación, disminución en la calidad del trabajo, desaparición de temas, aislamiento y quiebre de la comunidad, así como injusticias y burocratización extrema, son solo algunas de ellas. Como se puede observar, en la mayor parte de los casos, esto es sinónimo de pérdidas para el buen desarrollo de la actividad investigativa. Sin duda es posible adoptar medidas concretas con el fin de minimizar la proliferación de anomalías y distorsiones. En el caso chileno hay algunas que ya se han implementado tanto en las universidades como en las instituciones vinculadas al financiamiento de la investigación. Entre ellas están, por ejemplo, mejorar los sistemas de referato haciéndolo ciego, o incluyendo criterios cualitativos y de contenido como se hace ahora en el concurso Fondecyt de posdoctorado. Incentivar el trabajo colaborativo entre académicos es lo que al parecer se está haciendo con la creación de los proyectos Milenio de Investigación, pues en ellos se exige la participación de un grupo de académicos. Hay otras estrategias que se podría implementar, ninguna sirve, sin embargo, si no se ataca el fondo del problema. Ellas contribuyen tan solo a paliar los efectos de la mercantilización imperante, con la consecuente pérdida de valor y dignidad de la actividad académica. Montenegro (2007) ha escrito acertadamente que "[e]n este mundo en que domina la empresa, y la universidad en general vira a tornarse en una de ellas (aun las universidades públicas), el conocimiento y la educación en general se convierten en mercancías" (p. 9).

Marx decía del capitalismo que degradaba las cosas rebajándolas a mercancías, haciendo zozobrar su misma dignidad. En este caso, se degrada cuando se transforma el trabajo de investigación en una mera producción de textos, esto es, en una simple elaboración de objetos transables en el mercado de las publicaciones. Lo que genera el trabajo investigativo no es, sin embargo, tan solo mercancía cuya finalidad es ser ofrecida y transada en un mercado, sino que la investigación tiene un valor intrínseco, un 
valor que va más allá de los puntos otorgados por los paper que emanan de ella, más allá de las becas obtenidas, más allá de los financiamientos que se puedan conseguir. La investigación tiene un valor en sí misma, no como un medio o una moneda de cambio: no tiene precio, sino dignidad. Como decía Kant "[a]quello que tiene precio puede ser sustituido por algo equivalente, en cambio, lo que se halla por encima de todo precio y, por tanto, no admite nada equivalente, eso tiene una dignidad" (1989, p. 92). La dignidad, para Kant, alude a un "valor interno", que es completamente diferente del precio, que es un "valor relativo". Esto se ve claramente en el caso del "precio comercial", cuyo valor es relativo simplemente a lo que se esté dispuesto a pagar por un determinado objeto, servicio, etc. Cada investigación de un académico es única e irremplazable, posee un valor interno que la pone más allá de todo precio.

Entendida de esta forma, la cuestión pareciera ser si la investigación en particular y el trabajo académico en general son evaluables o tal vez sería mejor desistir de hacerlo. No han faltado quienes sostienen, con buenas razones, el término de toda evaluación. Con Murphy (2002) creo, sin embargo, que abandonar la evaluación no es una alternativa ni real ni positiva. Es un hecho que cada organización tiene una cierta cultura de la evaluación en la medida en que en ellas constantemente se "emiten juicios y se toman decisiones basadas en ellos" (p. 76). Esto parece ser una realidad indesmentible: siempre estamos evaluando y nos están evaluando, aunque ello no sea ni expresa ni estructuradamente. La evaluación es necesaria para saber cómo hemos avanzado, qué estamos haciendo bien y qué debemos mejorar o reparar. La solución, por lo tanto, no es ni puede ser desechar la evaluación, sino que transitar hacia un mejor modelo y hacia una cultura evaluativa más satisfactoria. Salir del esquema de la "evaluación de la productividad" que incomoda y atemoriza para avanzar hacia un sistema que no esté inspirado en el modelo industrial-empresarial. Esto, por supuesto, no es novedoso, pues hay y ha habido otros contextos y otros tiempos en los que la cultura evaluativa fue y es diferente. Lampert y Holgado (2001) señalan que:

Tradicionalmente la función principal [de la evaluación] era el castigo, la represión, la sanción, la selección, la clasificación y el control. En la línea progresista, la evaluación adquiere una postura de ayuda, de autoayuda, de acompañamiento, de apoyo, de crecimiento, de progreso. (p. 222)

Se trata de una manera alternativa de buscar, recopilar y conseguir in- 
formación, que no provoca la sensación incómoda de estar siendo inspeccionado o examinado desde la autoridad con la finalidad de tomar decisiones sobre nuestro futuro a partir de diagnósticos que no reflejan la realidad de nuestra actividad, y no tendría, por lo tanto, ninguna de las negativas consecuencias diagnosticadas.

\section{REFERENCIAS}

Bernasconi, A. (2010). La apoteosis del investigador y la institucionalización de la profesión académica en Chile. Estudios sobre educación, 19, 139-163.

Bermejo, J. C. (2009). La fábrica de la ignorancia. La universidad del "como si". Madrid: Akal.

Billig, M. (2013). Academic Words and Academic Capitalism. Athenea Digital 13(1), 7-12.

Bolseguí, M. y Fuguet, A. (2006). Cultura de evaluación: una aproximación conceptual. Investigación y Postgrado, 21(1), 77-98.

Corral, S. G. (2016). La lógica del funcionamiento de la universidad y el capitalismo cognitivo. Con-Ciencia Social, 20, 57-70.

Jofré, A. (2012, 1 de octubre). Felipe Cussen: "Los escritores deberían ver más tele para tomar conciencia de su nula importancia en la sociedad", Paniko. $c l$ [en línea].

Didou, S. (1995). Política de incentivo y sueldos para los académicos de la UAM. Muñoz y Rodríguez (coord.). Escenarios para la universidad contemporánea. Pensamiento Universitario, 83, 55-78.

Fernández, S. (1981, 11 de enero). Los Ministros responden 25 preguntas. El Mercurio, D1-2.

Greene, R. y Campos, D. (2012). Sobre la evaluación de la producción académica (Editorial). Bifurcaciones, Revista de estudios culturales urbanos, 11, 1-4. Recuperado de: http://www.bifurcaciones.cl/2012/12/editorial-evaluacion-academica/

Kant, I. (1989). Fundamentación de la Metafísica de las Costumbres. Madrid: Espasa-Calpe.

Lampert, E. y Holgado, M. A. (2001). La creación de cultura de evaluación institucional. Anales de pedagogía, 19, 221-239.

Márquez, T. y Cancino, V. (2013). La evaluación del desempeño académico universitario: antecedentes para su análisis en el contexto chileno. XIII Coloquio de Gestión Universitaria en América del Sur. Rendimiento Académico y eficacia social de la Universidad. Recuperado de https://repositorio. ufsc.br/bitstream/handle/123456789/116161/128.pdf?sequence $=1$

Montenegro, L. (2007). Editorial. Tábula Rasa, 6, 9-14. Recuperado de http://www.scielo.org.co/scielo.php?script=sci_arttext\&pid=S1794$24892007000100001 \& \operatorname{lng}=$ en\&tlng=es. 
Muñoz, H., García, S., y López, R. (2014). La evaluación de los académicos. Presentación del número especial de Perfiles Educativos 2013. La evaluación en la educación superior. Perfiles Educativos, XXXVI(146), 188-199.

Murphy, D. (2002). El desarrollo de una cultura de la evaluación. Itaka, Revista de lenguaje y cultura, 7(13), 75-85.

Ojeda, H. D. (2017). Evaluación del desempeño: crítica de la crítica. LinkedIn. Recuperado de: https://www.linkedin.com/pulse/evaluaci\%C3\%B3n-dedesempe\%C3\%B1o-cr\%C3\%ADtica-la-hugo-daniel-ojeda

Pérez, A. y Guzmán, M. (2015). Narrativa de los profesores investigadores en torno a las tensiones generadas por las condiciones laborales y evaluación de la producción académica. Administración y Organizaciones, 18(34), 95112.

Piña, J. M. (2013). Editorial. La evaluación al desempeño académico. Perfiles Educativos, $X X X V(141), 3-6$.

Rebolledo, R. (2014, 21 de abril). ¿Sirven los índices bibliométricos para medir la productividad científica? Red Seca, Revista de crítica política, social y cultural [en línea]. Recuperado de: http://www.redseca.cl/sirven-los-indicesbibliometricos-para-medir-la-productividad-cientifica/

Rorty, R. (1996). La profesionalización de la Filosofía y la cultura transcendentalista. Consecuencias del Pragmatismo (pp. 126-138). Madrid: Tecnos.

Rueda, M. y Landesmann, M. (coords.). (1999). ¿Hacia una nueva cultura de la evaluación de los académicos? México D.F.: Unam-Cesu, Pensamiento Universitario.

Santos Herceg, J. (2011). Filosofía de mercado. El filósofo profesional como MINI-PYME. Paralaje, 7, 45-63.

Santos Herceg, J. (2012). Tiranía del paper. Imposición institucional de un tipo discursivo. Revista chilena de literatura, 82, 197-217.

Santos Herceg, J. (2014, 12 de mayo). Fondecyt, Evolucionismo investigativo. Redseca. Revista de actualidad política, social y cultural. Recuperado de: http://www.redseca.cl/fondecyt-evolucionismo-investigativo/

Santos Herceg, J. (2015). Saberes académicos: de la producción textual a la creación de conocimiento. Revista Literatura: teoría, historia, crítica, 17(2), 97-112.

Santos Herceg, J. (2020). La Tiranía del paper. De la mercantilización a la normalización de las textualidades. Valdivia: Ediciones Universidad Austral de Chile.

Scherz, L. (2005). Los riesgos de una universidad competitiva. La Universidad chilena desde los extramuros (pp. 155-156). Santiago: Universidad Alberto Hurtado.

Schulz, P. y Katime, I. (2003). Los fraudes científicos. Revista Iberoamericana de Polímeros, 4(2), 1-90.

Tapia, A. y Varela, G. (2014). Evaluación individual y carrera académica: Impactos subjetivos. Argumentos 27(76), 81-101. Disponible 
en: http://www.scielo.org.mx/scielo.php?script=sci_arttext\&pid=S018757952014000300005\&lng=es\&tlng=es.

Valenzuela, J. R., Ramírez, M. S. y Alfaro, J. A. (2011). Cultura de evaluación en instituciones educativas. Comprensión de indicadores, competencias y valores subyacentes. Perfiles Educativos, XXXIII(131), 42-63.

Vidal, D. (2012). Análisis estratégico de una empresa del sector vitivinícola de la d.o. de Utiel-Requena. Valencia: Universidad Politécnica de Valencia. 